BMC

Immunology

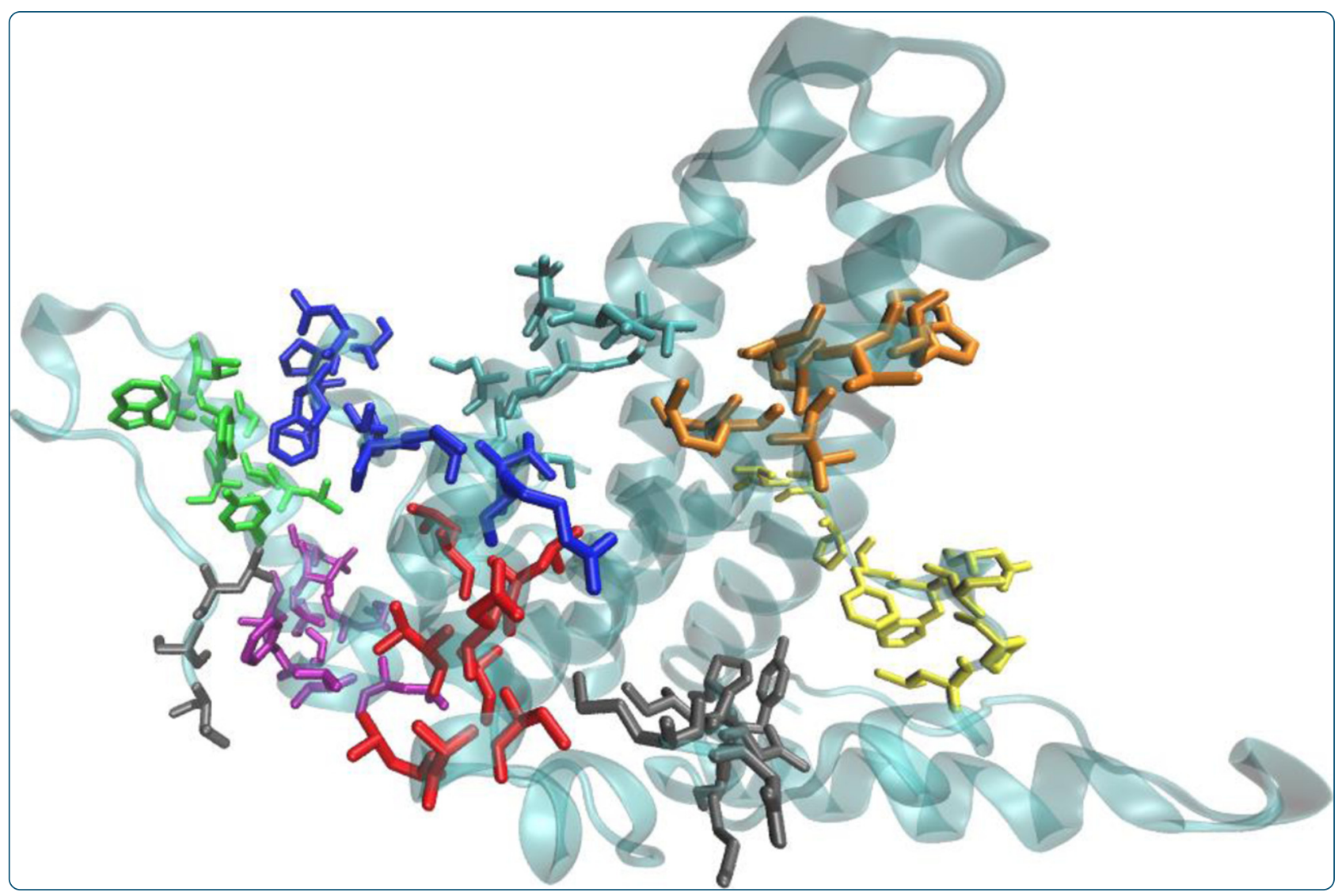

Immunogenicity of twenty peptides representing epitopes of the hepatitis B core and surface antigens by IFN- $\gamma$ response in chronic and resolved HBV

Brinck-Jensen et al.

C BioMed Central 


\title{
Immunogenicity of twenty peptides representing epitopes of the hepatitis $B$ core and surface antigens by IFN- $\gamma$ response in chronic and resolved HBV
}

\author{
Nanna-Sophie Brinck-Jensen ${ }^{1}$, Thomas Vorup-Jensen², Peter Derek Christian Leutscher ${ }^{1}$, Christian Erikstrup ${ }^{3}$ \\ and Eskild Petersen ${ }^{1 *}$
}

\begin{abstract}
Background: Patients with chronic hepatitis B virus infection (CHB) usually mount a modest T cell response against HBV epitopes. In order to determine immunogenic epitopes of HBV recognized by HBV-specific T cells, previous studies focused on previously confirmed HBV epitopes and assessed the $T$ cell response by the number of HBV-specific T cells by IFN- $\gamma$ ELISPOT.

Methods: We studied T cell functionality by combined in silico methods predicting HBV-specific epitopes and experimental investigations on the recognition of these epitopes. 30 chronic CHB patients and 10 patients with resolved HBV (RHB) were included in the study. We identified epitopes from the literature and by in silico analysis. These were evaluated for immunogenicity by use of synthetic peptides representing the epitopes through exposure to PBMCs from patients with CHB or RHB by IFN- $\gamma$ ELISPOT. The number of IFN- $\gamma$ producing cells (SFC), mean spot size (MSS) and stimulation index (SI) were recorded.

Results: The frequency of HBV-specific T cells producing IFN- $\gamma$ after stimulation with HBV epitopes was similar in CHB and RHB patients. CHB patients had a higher MSS SI than RHB patients. Patients not carrying the HLA-A2 genotype had higher SFC SI and MSS SI. Patients with HLA-A11 had higher MSS SI compared to non- HLA-A11 allele patients. HBeAg-positive patients had a lower MSS SI, and none of the HBeAg positive patients had the HLA-A11 genotype. We found 3 immunogenic epitopes not described previously.

Conclusion: IFN- $\gamma$ ELISPOT-determined MSS is an efficient marker for T cell recognition of epitopes. This experimental measure showed the in silico analysis for epitope prediction to be a valuable tool in future studies on HLA genotypes and HBV epitopes. This way our study now points to previously unappreciated consequences of carrying the HLA-A11 allele in terms of stronger immunity to HBV.
\end{abstract}

Keywords: Hepatitis B virus, T cell immunity, HLA genotypes, IFN- $\gamma$, ELISPOT, Epitope prediction

\section{Background}

Hepatitis B virus (HBV) is the cause of a spectrum of acute diseases including fatal hepatocellular necrosis. More than 350 million people have chronic HBV infection, which causes approximately one million deaths per year from the associated morbidities, liver cirrhosis and

\footnotetext{
* Correspondence: joepeter@rm.dk

'Department of Infectious Diseases, Aarhus University Hospital, Palle Juul-Jensens Boulevard 99, 8200 Aarhus N, Skejby, Denmark Full list of author information is available at the end of the article
}

cancer [1]. Several lines of evidence suggest that HBV infection induces suppression of the immune response to the viral components as a result of both viral tropism and antigen release.

In patients with chronic $\mathrm{HBV}$ infection $\mathrm{HBV}$-specific $T$ cells egress into the liver but present only a modest anti viral response $[2,3]$. By contrast, patients with an acute, self-limited HBV infection usually mount a vigorous polyclonal CTL response targeting multiple HBV epitopes [4] and with sufficient longevity to be 
detectable several years after infection $[5,6]$. Here we show that this is a conclusion not always cogent in the case of patients with a resolved HBV more than two years ago.

As part of the studies to understand the immune response to HBV infection, an important part of the efforts has been focused on identifying highly immunogenic CTL epitopes. One approach involves in silico predictions on the dissociation constant $\left(K_{\mathrm{D}}\right)$ for the binding of antigenderived peptides to the Human Leukocyte Antigen (HLA) molecules, typically accompanied by experimental testing of CTL response to these peptides or experimentally tested ability of HLA molecules to bind these peptides. A number of studies reported that binding between HLA molecules and antigenic peptides characterized by $K_{\mathrm{D}}<500 \mathrm{nM}$ appears to enable CTL responses [7]. However, other studies suggest that the effects of antigenic epitopes not always correlate with the affinity of the epitope-containing peptide to HLA $[8,9]$. Previous studies evaluated the immune response to HBV infection by testing previously confirmed HBV epitopes and assessed the $\mathrm{T}$ cell response by determining the frequency of reactive $\mathrm{T}$ cells, typically by IFN- $\gamma$ enzyme-linked immunosorbent spot (ELISPOT) analysis. From such studies it was suggested that the frequencies of antigen-specific CTLs may not be the major determinant of immune-mediated protection in chronic hepatitis B, nor should immunotherapeutic approaches only aim at raising the frequency of $\mathrm{HBV}$-specific T cells. Indeed, $\mathrm{T}$ cell functionality, such as ability to produce cytokines, may also be important parameters [10]. However, the correlation between HLA affinity for epitope-containing peptides and $\mathrm{T}$ cell cytokine production as estimated by ELISPOT has not been comprehensively studied in the context of chronic $\mathrm{HBV}$ infection.

\section{Objectives}

Here, we combine in silico methods for predicting HBVspecific CTL epitopes and compare with the T cell response in vitro. By comparing cells from patients with chronic HBV infection (CHB) and patients with resolved HBV infection (RHB), we show that the calculations were efficient in predicting immunogenic epitopes recognized by $\mathrm{T}$ cells from $\mathrm{CHB}$ patients. Indeed, $\mathrm{T}$ cell functionality calculated from the amount of IFN- $\gamma$ produced was increased in CHB patients with HLA-A11 genotype.

\section{Methods}

\section{Patients}

The study population consisted of patients with $\mathrm{CHB}$, i.e., positive HBsAg status for more than six months, followed in Aarhus University Hospital, and former patients with RHB previously seen in Aarhus University
Hospital. The diagnosis of acute HBV was based on clinical and biochemical evidence of acute liver injury according to standard diagnostic criteria of acute HBV infection, i.e. elevated liver enzymes, positive HBsAg and IgM-antibodies against $\mathrm{HBcAg}$ [11] and reviewed in [12]. Written consent was obtained from each participant, including consent to publish all personal information contained in Table 3. The study was approved by the The Central Denmark Region Committees on Health Research Ethics, ref. number M-40-12 and the National Data Protection Agency journal number 2012-41-0028.

\section{Virological analyses}

HBsAg, HBeAg, anti-HBe, anti-HBc, anti-HBs, HIV Ag/ $\mathrm{Ab}$, and anti-HCV were determined by commercially available chemiluminescense assays on the Architect system (Architect, Abbott Laboratories, Abbott Park, Illinois, USA). HBV DNA levels were quantified by commercial hybridization assay.

\section{Peripheral blood mononuclear cells (PBMCs)}

PBMCs were isolated from $50 \mathrm{~mL}$ of fresh whole blood in $6 \times 8 \mathrm{~mL}$ cell preparation tubes prefilled with $1 \mathrm{~mL}$ $0.1 \mathrm{M}$ sodium citrate and $3 \mathrm{~g}$ of polyester gel, $2.0 \mathrm{~mL}$ of FICOLL $^{\mathrm{mm}}$ Hypaque $^{\mathrm{mm}}$ solution (BD Vacutainer ${ }^{\circ} \mathrm{CPT}^{\mathrm{Tm}}$ ). Pellet was resuspended in RPMI-1640 with $20 \%$ (v/v) FCS and $10 \%(\mathrm{v} / \mathrm{v})$ DMSO and frozen in liquid nitrogen.

\section{HLA loci genotyping}

High-resolution HLA class I typing was performed using Sequence Based Typing method with PCR sequencing templates performed on both strands. Sequencing DNA templates was produced by locus- and group-specific amplifications that include exon 2 and 3, which contain the antigen recognition sites. Class I sequencing primers where the common sequences for all loci in the intron/exon boundary regions and a total of 40 locus and group-specific primers were used to amplify the target sequences (HistoGenetics LLC, Ossining, NY, USA).

\section{Epitope selection}

Published reports on acute and chronic HBV patient and response to various HBV epitopes was studied and compared to NetMHC version 3.2 predictions of 8-mer epitopes, using Artificial Neural Networks Approximation (www.cbs.dtu.dk/services/) [6, 8, 9, 13-19]. Computer predictions were made on class I genotypes HLA-A11, HLAA24 and HLA-A2 since these genotypes covered the majority of our patientpopulation. The surface sequences vary greatly among different $\mathrm{HBV}$ genotypes and subtypes [20] and we observed single and double residue variations 
between the published sequences and sequences found in the database of the computer algorithm. For this reason we were not able to directly compare the findings of the published reports with the computer predictions. The computer predicted epitopes were designed by cross matching the different HLA subtypes and HBV genotypes of the study population. According to classifications made earlier [21], a dissociation constant $K_{\mathrm{D}}<50$ $\mathrm{nM}$ predicted strong binding, 50-500 nM weak binding, and $K_{\mathrm{D}}>500 \mathrm{nM}$ predicted essentially no binding. Analysis of protein parameters isoelectric point (pI) [22], length, instability index [23] and aliphatic index [24] were performed on each epitope (http://web.expasy.org/protparam/).

\section{Peptides mimetics of HBsAg-specific epitopes in ELISPOT assays}

Twenty HBsAg and HBcAg epitopes were purchased from GL Biochem (Shanghai, China), with a purity $>95 \%$ as estimated from mass spectometry. We used HLA class Irestricted $\mathrm{T}$ cell epitopes from human cytomegalovirus, Epstein Barr virus and influenza virus (CEF) for positive control (CTL-Europe GmbH, Germany).

Enzyme-linked immunospot (ELISPOT) assays were performed using the 20 different peptides seeded in separate wells. Briefly, 96-well plates (Multiscreen-IP; Millipore S.A.S., Molsheim, France) were coated overnight at $4{ }^{\circ} \mathrm{C}$ with $100 \mu \mathrm{L} /$ well capture mouse antihuman IFN- $\gamma$ monoclonal antibody (AH diagnostics, Aarhus, Denmark). Plates were washed twice with ELISPOT coating buffer and blocked with CTL serum-free media for $1-2 \mathrm{~h}$ at room temperature (CTL-Europe GmbH, Germany). PBMCs $\left(3 \times 10^{5} /\right.$ well) were thawed and suspended in CTL serum-free media then seeded in triplicate for each individual peptide. Plates were incubated for $48 \mathrm{~h}$ at $37{ }^{\circ} \mathrm{C}$ and washed with PBS and $0.05 \%$ Tween-20. $100 \mu \mathrm{L} /$ well biotinylated secondary mouse anti-human IFN- $\gamma$ monoclonal antibody was added according to manufacturer recommendations. After $2 \mathrm{~h}$ incubation at room temperature, plates were washed four times with PBS and $0.05 \%$ Tween-20, $100 \mu \mathrm{l}$ of Avidin-HRP solution was added to the wells, and the plates were incubated for further $45 \mathrm{~min}$ at room temperature. Plates were washed 3 times with PBS and $0.05 \%$ Tween-20, and 2 times with PBS alone, and $100 \mu \mathrm{l}$ of AEC substrate solution (3-amino-9-ethyl carbazole) was added. After 10-15 $\mathrm{min}$, the colorimetric reaction was stopped by washing three times with distilled water. Plates were air dried, and spots were counted and analyzed using an automated ELISPOT reader (CTL-Immunospot S6 Analyzer, CTL GmbH, Germany). The T cell response was assessed as spot forming cells (SFC) and mean spot size (MSS). To exclude subjective assessment, whether the background were related to the actually response, we decided to use the stimulation index (SI) for analysis, calculated by dividing the value of the stimulated sample with the value of the unstimulated control. Four uninfected individuals (with clean HBV serology) were included to exclude unspecific findings (data not shown). All patients responded vigorously to the positive CEF control.

\section{Statistics}

Statistical analysis was performed using GraphPad Prism 6 (๑2014 GraphPad Software, Inc) and STATA/IC 13.1 (๑2014 StataCorp, LP). Non-parametric measures were analysed by Spearman's correlation, Mann-Whitney $U$ test, Kruskal-Wallis test with Dunn's correction for multiple comparison while parametric data were assessed by Student's T-test and one-way analysis of variance (ANOVA).

\section{Results}

\section{HLA genotypes and epitopes}

Ten experimentally confirmed (EC) HBsAg and $\mathrm{HBcAg}$ epitopes were chosen from the literature, and 10 8-mer HBsAg and HBcAg epitopes were chosen based on the computer predictions (CP) of HLA class I binding to the epitopes (Tables 1 and 2). Among CHB patients, 12/30 (40\%) were HLA-A*02:01, 1/30 (3\%) HLA-A*02:03, $1 / 30$ (3 \%) HLA-A*02:06 and 1/30 (3 \%) HLA$\mathrm{A} * 02: 17$. Among RHB patients, 6/10 (60 \%) were HLA-A*02:01. We included one surface epitope tested among patients with HLA-A*11 genotype and one tested among HLA-A*24 genotype patients. Among the patients, $5 / 30$ (17 \%) $\mathrm{CHB}$ patients and $2 / 10$ (20\%) RHB patients had HLA-A*11 genotype, and 6/30 (20\%) CHB patients had HLA-A*24 genotype. No RHB patients were HLA-A*24 genotype. Characteristics of patients are shown in Table 3.

\section{IFN- $\gamma$ ELISPOT}

Age-related data of the $\mathrm{CHB}$ and RHB patients were tested for normality and equal SD and analysed by students $t$-test. No significant difference was found between the two groups (difference in year: -3.16 (CI: $-14.1-7.8$ ), $p=0.72$ ). To test whether the response to HBV epitopes of the CHB patients depended on age, ethnicity and gender, Kruskal Wallis oneway analysis of variance were performed on each separate response parameter, SFC and MSS. No significant difference of response was found among the four ethnic groups Black African $(n=2)$, Arab $(n=1)$, Asian $(n=12)$ and White European $(n=15)$, $p=0.68$ for MSS, $p=0.12$ for SFC. Furthermore no significant difference were found among males and females, $p=0.55$ for MSS, $p=0.13$ for SFC. We have previously reported that age is an important determinant in 
Table 1 HLA class I restricted epitopes (I)

\begin{tabular}{|c|c|c|c|c|}
\hline Number & Residues & Sequence & $\mathrm{HLA}$ & Reference \\
\hline HBsEC-1 & $20-28$ & FLLTRILTI & $A^{*} 02: 01,02: 05,02: 06$ & [13] \\
\hline HBsEC-2 & $88-96$ & LLCLIFLLV & A2 & {$[9,14]$} \\
\hline HBsEC-3 & $95-104$ & LVLLDYQGML & A2 & {$[8]$} \\
\hline HBsEC-4 & $172-180$ & WLSLLVPFV & $A^{*} 02: 01,02: 02,02: 03,02: 05,02: 06$ & {$[6,8,9,14,15]$} \\
\hline HBsEC-5 & $207-216$ & SIVSPFIPLL & A2 & [14] \\
\hline \multirow[t]{3}{*}{$\mathrm{HBsCP}-6^{\mathrm{b}}$} & $169-176$ & FLGPLLVL & $\mathrm{A} 2^{\mathrm{a}}$ & \\
\hline & 180-187 & & & \\
\hline & $179-188$ & & & \\
\hline \multirow[t]{3}{*}{$\mathrm{HBsCP}-7^{\mathrm{b}}$} & $72-79$ & LLGWSPQA & $\mathrm{A} 2^{\mathrm{a}}$ & \\
\hline & $61-68$ & & & \\
\hline & $71-78$ & & & \\
\hline \multirow[t]{3}{*}{$\mathrm{HBsCP}-8^{\mathrm{b}}$} & $259-266$ & LLLCLIFL & $\mathrm{A} 2^{\mathrm{a}}$ & \\
\hline & $248-255$ & & & \\
\hline & $258-265$ & & & \\
\hline \multirow[t]{3}{*}{$\mathrm{HBsCP}-9^{\mathrm{b}}$} & $333-370$ & FLWEWASA & $\mathrm{A} 2^{\mathrm{a}}$ & \\
\hline & $332-339$ & & & \\
\hline & $322-329$ & & & \\
\hline \multirow[t]{3}{*}{$\mathrm{HBsCP}-10^{\mathrm{b}}$} & $129-136$ & PAGGSSSG & $\mathrm{A} 2^{\mathrm{a}}$ & \\
\hline & $140-147$ & & & \\
\hline & $139-146$ & & & \\
\hline $\mathrm{HBCEC}-11$ & $18-27$ & FLPSDFFPSV & $A^{*} 02: 01,02: 05,02: 06$ & {$[6,8,9,14-17]$} \\
\hline $\mathrm{HBCEC}-12$ & $88-96$ & YVNVNMGLK & A11 & [18] \\
\hline $\mathrm{HBCEC}-13$ & $107-115$ & CLTFGRETV & A2 & {$[8]$} \\
\hline $\mathrm{HBCEC}-14$ & $117-125$ & EYLVSFGWW & A24 & [19] \\
\hline $\mathrm{HBCEC}-15$ & 139-148 & ILSTLPETTV & A2 & {$[8]$} \\
\hline $\mathrm{HBCCP}-16$ & $141-148$ & TLPETTW & A2 & \\
\hline $\mathrm{HBcCP}-17$ & $160-168$ & PSPRRRRS & A2 & \\
\hline $\mathrm{HBcCP}-18$ & $64-71$ & LMTLATWV & $\mathrm{A} 2$ & \\
\hline HBcCP-19 & $29-36$ & LLDTASAL & A2 & \\
\hline $\mathrm{HBcCP}-20$ & $107-114$ & LTFGRETV & $\mathrm{A} 2$ & \\
\hline
\end{tabular}

Name and amino acid position of the 20 epitopes. HLA genotype indicates which genotypes were tested in previous studies (HBsEC1-5 and HBcEC11-15), or which genotypes we stratified for in the in silico analysis (HBsCP6-10 and HBcCP16-20)

HBsEC HBsAg experimentally confirmed, $H B s C P$ HBsAg computer predicted, $H B C E C$ HBcAg experimentally confirmed, $H B C C P$ HBCAg computer predicted

aall subtypes

${ }^{b}$ differences of sequence position among HBV genotypes was observed for in silico prediction of $\mathrm{HBsAg}$

humoral and $\mathrm{T}$ cell responses to immunization with hepatitis B surface antigen [25] so to test whether age were related to the response to HBV epitopes, we divided patients in three groups: $23-30$ years $(n=6), 31-49$ years $(n=13)$ and 50-73 $(n=11)$. No significant difference of response were found between the groups, $p=0.15$ for MSS, $p=0.45$ for SFC. Due to the limited number of patients in the RHB group, the statistical power was not strong enough to make subanalysis.

The numbers of $\mathrm{HBV}$-specific $\mathrm{T}$ cells producing IFN- $\gamma$ after stimulation with $\mathrm{HBV}$ epitopes were similar in $\mathrm{CHB}$ and $\mathrm{RHB}$ patients. Furthermore, the chronic patients surprisingly had a significantly higher MSS SI (Fig. 1). Comparison of the area under the curve (AUC) based on the response profiles of SFC and SFC $\mathrm{x}$ MSS, found that difference in response profiles did reach statistical significance when comparing SFC $x$ MSS area $(p<0.0001)$. When stratifying the analysis for patients with HLA-A2 and non HLAA2 genotype, the group of non HLA-A2 were found with significantly higher SI of SFC and MSS, the results being even more distinct when only the $\mathrm{CHB}$ patients 
Table 2 HLA class I restricted epitopes (II)

\begin{tabular}{|c|c|c|c|c|}
\hline Number & $\begin{array}{l}\text { Response } \\
\text { AHB }\end{array}$ & Response $\mathrm{CHB}$ & $K_{D}$ & Reference \\
\hline HBsEC-1 & $14 / 23$ & $\mathrm{~N} / \mathrm{A}$ & $N / A$ & [13] \\
\hline HBsEC-2 & $6 / 13$ & $1 / 15$ & N/A & {$[9,14]$} \\
\hline HBsEC-3 & N/A & $16 / 17$ & N/A & {$[8]$} \\
\hline HBsEC-4 & $42 / 56$ & $5 / 33$ & N/A & {$[6,8,9,14,15]$} \\
\hline HBsEC-5 & $2 / 4$ & $0 / 12$ & N/A & [14] \\
\hline HBsCP-6 & & & $<50 \mathrm{nM}$ & \\
\hline $\mathrm{HBsCP}-7$ & & & $<50 \mathrm{nM}$ & \\
\hline $\mathrm{HBsCP}-8$ & & & $<50 \mathrm{nM}$ & \\
\hline $\mathrm{HBsCP}-9$ & & & $<50 \mathrm{nM}$ & \\
\hline $\mathrm{HBsCP}-10$ & & & $>500 \mathrm{nM}$ & \\
\hline $\mathrm{HBCEC}-11$ & $41 / 59$ & $9 / 30$ & $50-10,000 \mathrm{nM}$ & {$[6,8,9,14-17]$} \\
\hline $\mathrm{HBCEC}-12$ & N/A & $1 / 1$ & N/A & [18] \\
\hline $\mathrm{HBCEC}-13$ & N/A & $2 / 5$ & $>50 \mathrm{nM}$ & [8] \\
\hline $\mathrm{HBCEC}-14$ & $7 / 12$ & $0 / 11$ & $>500 \mathrm{nM}$ & [19] \\
\hline $\mathrm{HBCEC}-15$ & $\mathrm{~N} / \mathrm{A}$ & $15 / 18$ & $>50 \mathrm{nM}$ & {$[8]$} \\
\hline $\mathrm{HBCCP}-16$ & & & $<50 \mathrm{nM}$ & \\
\hline $\mathrm{HBcCP}-17$ & & & $>500 \mathrm{nM}$ & \\
\hline $\mathrm{HBCCP}-18$ & & & $<50 \mathrm{nM}$ & \\
\hline $\mathrm{HBCCP}-19$ & & & $<50 \mathrm{nM}$ & \\
\hline $\mathrm{HBCCP}-20$ & & & $50-500 \mathrm{nM}$ & \\
\hline
\end{tabular}

All $K_{\mathrm{D}}$ values are in silico predictions by NetMHC version 3.28 mer predictions. $\mathrm{HBsEC}: \mathrm{HBsAg}$ experimentally confirmed; $\mathrm{HBsCP}: \mathrm{HBsAg}$ computer predicted; $\mathrm{HBCEC}$ : $\mathrm{HBCAg}$ experimentally confirmed; $\mathrm{HBCCP}$ : $\mathrm{HBCAg}$ computer predicted. $N / A$ : Not available, AHB and $C H B$ referres to number of responders in previous studies of acute hepatitis B (AHB) and chronic hepatitis B patients (CHB)

were included in the analysis, MSS: $p<0.0001$, SFC: $p=0.0099$ (Fig. 2). AUC analysis confirmed the response profile to be significantly different. Analysing the SI stratifying for various HLA genotypes, only patients with HLAA11 had significantly stronger SI of MSS (Fig. 3). AUC analysis of $\mathrm{CHB}$ patients with HLA-A11 genotype compared to RHB patients with HLA-11 genotype and CHB patients with HLA-A2 genotype respectively, revealed statistical significance in SFC x MSS response profile $(p<0.0001)$. Additionally, $\mathrm{HBeAg}$ positive patients, all with higher viral load, had a significantly lower SI of MSS, and none of the $\mathrm{HBeAg}$ positive patients had HLA-A11 genotype (Fig. 4).

\section{Correlations of SFC and MSS}

To determine whether number of spots correlated with spot size, e.g. is the frequency of HBV specific T cells proportional with the functionality, we correlated SFC and MSS in all different groups. Using spearman's correlation, no significance was found, but a trend towards correlation was found in all groups (data shown for chronic patients with/without HLA-A2 genotype in Fig. 2c).

\section{Computer prediction of immunoreactive epitopes}

We compared the epitopes from the literature (experimentally confirmed, EC, epitopes 1-5 and 11-15) with epitopes computer predicted (CP, epitopes 6-10 and 16-20) to assess the ability of the computer algorithm to determine $\mathrm{HBV}$ epitopes. We compared the SI in 4 groups: Chronic and resolved HBV, HLA-A2 genotype and non HLA-A2 genotype, HLA-A11, HLA-A2 and other HLA genotypes, HBeAg positive and $\mathrm{HBeAg}$ negative patients. We analysed $\mathrm{HBsAg}$ and $\mathrm{HBcAg}$ epitopes together and separately, respectively, and found no significant difference in response towards epitopes experimentally confirmed compared with epitopes computer predicted.

Analysis of protein parameters included isoelectric point, length, instability index and aliphatic index and were performed for each epitope. We analysed the parameters in 4 groups: HBsAg epitope 1-5 EC, HBsAg epitope 6-10 CP, HBcAg epitope 11-15 EC, and HBcAg epitope 16-20 CP. No correlation between the different parameters and SI were found (data not shown). No significant difference where found between the groups (data not shown).

\section{Epitope assessment}

We assessed the individual epitopes capability of eliciting specific $\mathrm{T}$ cell response, by the amount of IFN- $\gamma$ produced. MSS SI varied widely within the groups. We found that 6 epitopes generally elicited a higher SI in all groups (Table 4). Three epitopes were already experimentally confirmed (EC-1, -4 and -11 ), and three epitopes where computer predicted (CP-7, -9 and -17$)$.

\section{Discussion}

Based on findings in several past studies, we hypothesized that a stronger IFN- $\gamma$ response would be produced in PBMC from resolved $\mathrm{HBV}$ patients compared to PBMC from chronic HBV patients when stimulating with 20 individual HBV epitopes and quantifying IFN- $\gamma$ response by of number of spot forming units and the amount of IFN- $\gamma$ produced. Surprisingly, T cells from CHB patients recognized a similar number of CTL epitopes compared to $\mathrm{T}$ cells from RHB patients. We observed a relatively unimpaired cytokine response with higher levels of IFN- $\gamma$ in $\mathrm{CHB}$ patients, in patients without HLA-A2 genotype, patients with HLA-A11 genotype, and we found lower levels of IFN- $\gamma$ production in patients with high viral load (HBeAg positive). These results suggest that the impaired immune response in $\mathrm{CHB}$ is not solely due to impaired production of IFN- $\gamma$. Indeed, IFN- $\gamma$ remains as an important component of the overall immune response required combating infection with $\mathrm{HBV}$. Note that in our study the average 
Table 3 Patient characteristics

\begin{tabular}{|c|c|c|c|c|c|}
\hline $\mathrm{ID}$ & Age & Sex & Ethnicity & HLA class I & $\mathrm{HBeAg}$ \\
\hline $\mathrm{Cl}$ & 57 & $\mathrm{~F}$ & Black African & A2A24 B44B58 C3C16 & Neg \\
\hline$C 2$ & 46 & $\mathrm{~F}$ & Asian & A24A31 B35B51 C1C14 & Neg \\
\hline C3 & 43 & M & Arab & A2A3 B44B47 C6C16 & Neg \\
\hline C4 & 35 & M & Asian & A11A33 B44B55 C3C7 & Neg \\
\hline C5 & 52 & M & Asian & A2A33B40B51 C14C15 & Pos \\
\hline C6 & 33 & M & White European & A2 B14B18 C7C8 & Neg \\
\hline C7 & 49 & $\mathrm{~F}$ & Asian & A1A11 B35B52 C4C7 & Neg \\
\hline $\mathrm{C} 8$ & 39 & $\mathrm{~F}$ & White European & A3A74B15B35 C4 & Neg \\
\hline C9 & 29 & $\mathrm{~F}$ & White European & A1A32 B40B44 C3C16 & Neg \\
\hline $\mathrm{C} 10$ & 65 & M & White European & A2A29 B7B44 C7C16 & Pos \\
\hline $\mathrm{C} 11$ & 30 & $\mathrm{~F}$ & White European & A2 B38B51 C12C15 & Neg \\
\hline $\mathrm{C} 12$ & 26 & $\mathrm{~F}$ & White European & A2A24 B18B38 C7C12 & Neg \\
\hline $\mathrm{C} 13$ & 43 & $\mathrm{~F}$ & Asian & A2A26 B56B59 C1C7 & Neg \\
\hline $\mathrm{C} 14$ & 46 & M & White European & A1A2 B37B51 C6C15 & Neg \\
\hline C15 & 73 & M & White European & A2A3 B7 C7 & Neg \\
\hline $\mathrm{C} 16$ & 53 & M & Asian & $\mathrm{A} 11 \mathrm{~A} 24 \mathrm{~B} 13 \mathrm{~B} 18 \mathrm{C} 3 \mathrm{C} 7$ & Neg \\
\hline $\mathrm{C} 17$ & 29 & $\mathrm{~F}$ & White European & A2 B13 C6 & Neg \\
\hline C18 & 61 & $\mathrm{~F}$ & Asian & A11A33 B13B58 C3 & Neg \\
\hline C19 & 40 & $\mathrm{~F}$ & Asian & A11A33 B44B59 C1C14 & Neg \\
\hline $\mathrm{C} 20$ & 51 & $\mathrm{~F}$ & Black African & A29A30 B18B45 C6C7 & Pos \\
\hline $\mathrm{C} 21$ & 34 & $\mathrm{~F}$ & Asian & $\mathrm{A} 24 \mathrm{~A} 26 \mathrm{~B} 13 \mathrm{~B} 40 \mathrm{C} 3 \mathrm{C} 6$ & Pos \\
\hline $\mathrm{C} 22$ & 30 & M & White European & A2A26 B38B51 C12C15 & Neg \\
\hline $\mathrm{C} 23$ & 62 & $\mathrm{~F}$ & White European & A2A68 B15B44 C3C7 & Neg \\
\hline $\mathrm{C} 24$ & 51 & M & White European & A2A3 B7B18 C7 & Neg \\
\hline $\mathrm{C} 25$ & 61 & M & White European & A2A26 B7B51 C1C12 & Neg \\
\hline $\mathrm{C} 26$ & 34 & $\mathrm{~F}$ & Asian & A24A26 B13B40 C3C6 & Pos \\
\hline $\mathrm{C} 27$ & 61 & $\mathrm{~F}$ & White European & N/A & Neg \\
\hline $\mathrm{C} 28$ & 49 & M & Asian & N/A & Neg \\
\hline C29 & 37 & M & Asian & N/A & Pos \\
\hline C30 & 23 & M & White European & N/A & Neg \\
\hline R31 & 40 & $\mathrm{~F}$ & White European & A2 B15B44 C1C5 & \\
\hline R32 & 30 & $\mathrm{~F}$ & White European & A2A68 B35B44 C4C5 & \\
\hline R33 & N/A & N/A & White European & A2A26 B38B40 C12C15 & \\
\hline R34 & 48 & M & White European & A23A26 B35B44 C4 & \\
\hline R35 & 65 & $\mathrm{~F}$ & White European & A1A2 B7B8 C7 & \\
\hline R36 & 43 & $\mathrm{~F}$ & White European & $\mathrm{A} 1 \mathrm{~A} 11 \mathrm{~B} 8 \mathrm{~B} 15 \mathrm{C7}$ & \\
\hline R37 & 38 & M & White European & A2A11 B15B55 C3 & \\
\hline R38 & 69 & $\mathrm{~F}$ & White European & A2 B7B8 C7 & \\
\hline R39 & 73 & $\mathrm{~F}$ & White European & N/A & \\
\hline R40 & 25 & $\mathrm{~F}$ & White European & N/A & \\
\hline
\end{tabular}

Normal ALT levels were found in all patients except patient C18 and C19 where ALT levels were elevated to 59 and $66 \mathrm{IU} / \mathrm{mL}$ (normal range for females is $10-45 \mathrm{IU} / \mathrm{mL}$ ). No patients were double positive or double negative for HBeAg/anti-HBeAg. Median HBV DNA in the HBeAg positive patients were $81,000 \mathrm{IU} / \mathrm{mL}$ $(2-400.000 \mathrm{IU} / \mathrm{mL})$ and $0.019 \mathrm{IU}(0-5500 \mathrm{IU} / \mathrm{mL})$ in the HBV negative patients, no statistics were made on HBV genotype since quantification was not possible in 12 of the 30 patients. N/A: not available; F: female; M: male; Pos: positive; Neg: negative 


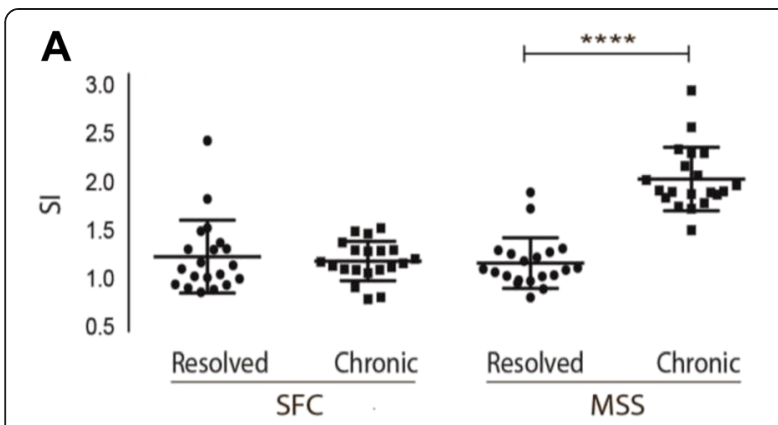

B

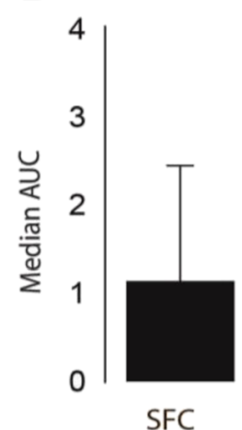

(R)

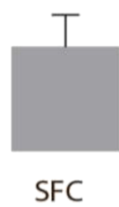

(C)

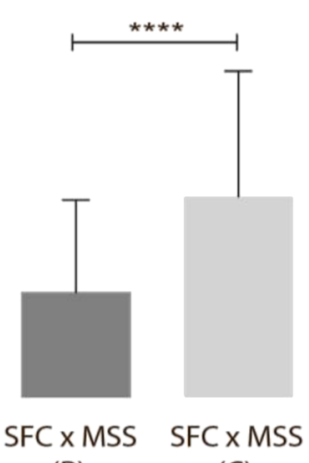

$(\mathrm{R})$
C

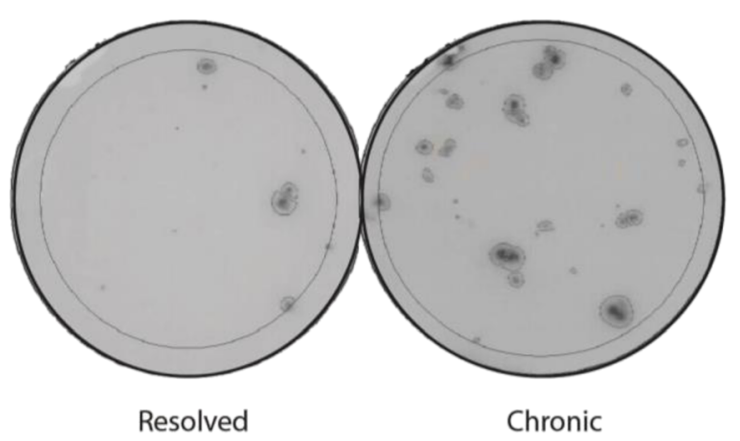

Fig. 1 ELISPOT results of chronic and resolved HBV patients. a Stimulation index (SI) for CHB and RHB patients. Each datapoint represents the mean response to each individual epitope. No difference where found in the frequency of spot forming cells. The CHB patients had a significantly higher amount of IFN- $\gamma$ production. Unpaired two-tailed $t$-test with equal SD, $N=10$ RHB patients, $N=30$ CHB patients, ${ }^{* * * *}$ indicates $p<0.0001$. b AUC showed that difference in response profiles did reach statistical significance when comparing SFC $\times$ MSS area, Dunn's multiple comparisons test, $\mathrm{R}$; resolved, $\mathrm{C}$; chronic, ${ }^{* * * *}$ Indicates $p<0.0001$. c Picture from the data-analysis of a RHB and CHB patient. Large circle indicates the counted area. Small circles indicate the counted spots stimulation index did not exceed 6, which still indicates a low IFN- $\gamma$ production. Since the majority of epitopes were designed to give a strong response in patients with HLA-A2 genotype, with little difference among HLA$\mathrm{A}^{*} 02$ subtypes, and since we found a stronger response

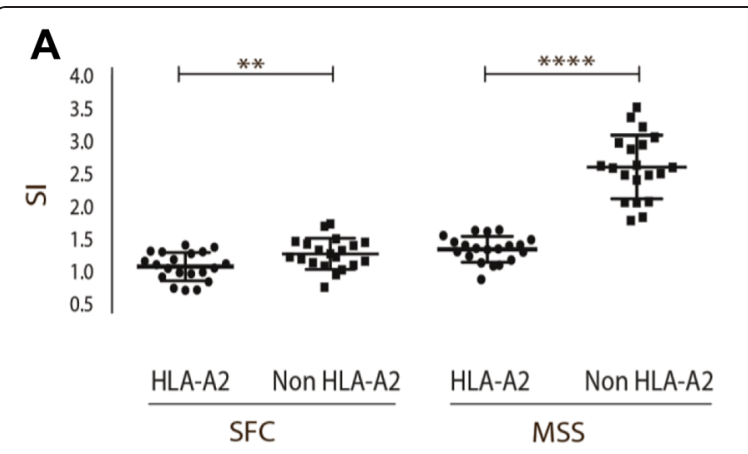

\section{B}

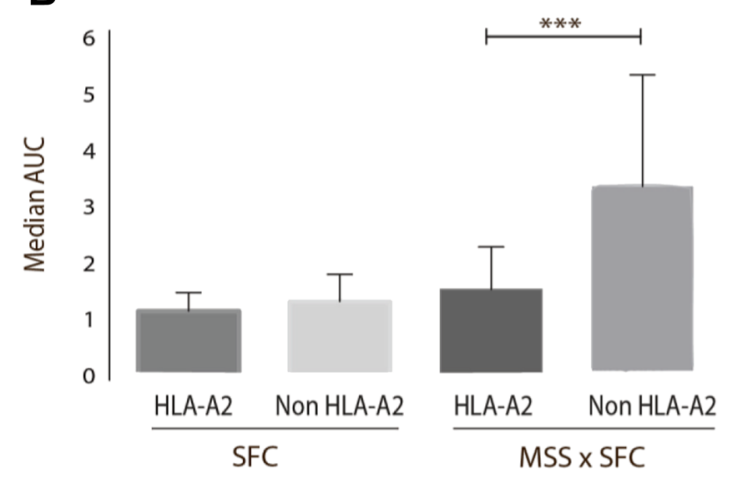

C
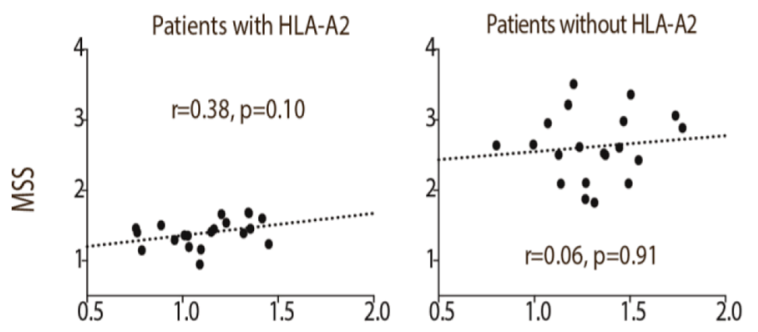

SFC

Fig. 2 ELISPOT results of chronic HLA-A2 patients. a Stimulation index (SI) for CHB patients divided in two groups: Patients with the HLA-A2 genotype and patients without HLA-A2 genotype. Each datapoint represents the mean response to each individual epitope. The patients without HLA-A2 genotype had a significantly higher amount of IFN- $\gamma$ production. If we included RHB patients in the analysis, the results were still significant. Unpaired two-tailed $t$-test with equal SD, $N=15$ in each group, ${ }^{* * *}$ indicates $p<0.0001$, ** indicates $p=0.0099$. b AUC showed that difference in response profiles did reach statistical significance when comparing SFC x MSS area, Kruskal-Wallis (Dunn's) multiple comparisons test, ${ }^{* * *}$ indicates $p=0.0009$. c Spot number correlated with spot size. No significant correlation was found in patients with HLA-A11, this may suggest HLA-A11 is protective. No patients were both HLA-A11 and HBeAg positive and this supports $\mathrm{HBeAg}$ as a virulence factor and that control of HBV is more complex than $\mathrm{T}$ cell capability of IFN- $\gamma$ production alone [26]. Other studies 


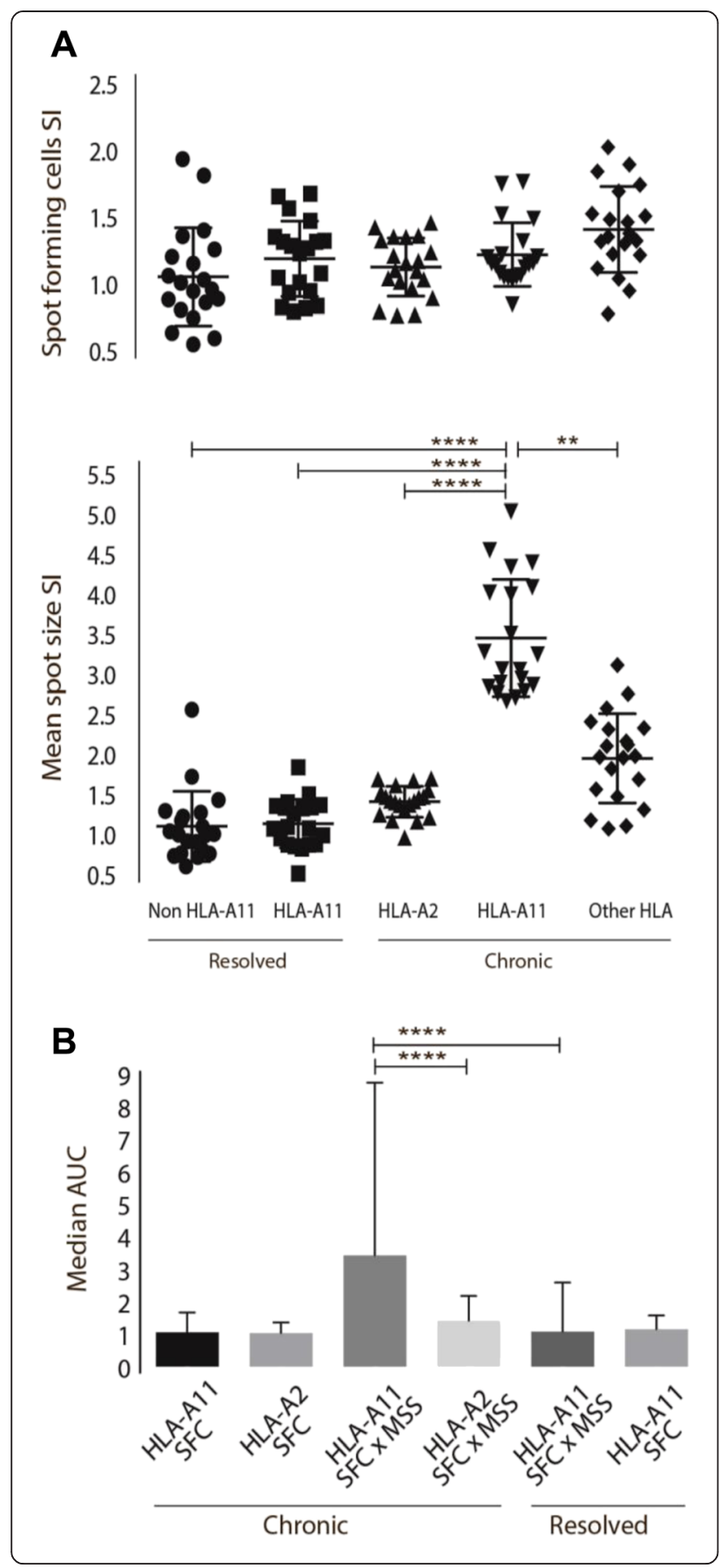

Fig. 3 ELISPOT results of HLA-A11 and non-HLA-A11 patients. a Stimulation index (SI) for patients divided in 5 groups. Each datapoint represents the mean response to each individual epitope. CHB patients with HLA-A11 had significantly higher SI of MSS compared to all other group. No significance were found when analysis spot forming cells; R: resolved; C: chronic. Unpaired one-way ANOVA, Kruskal-Wallis (Dunn's) multiple comparison test, Non HLA-A11 (R) $(N=8)$, HLA-A11 (R) $(N=2)$, HLA-A2 (C) $(N=15)$, Other HLA (C) $(N=10)$, *** indicates $p<0.0001$, top line: $95 \% \mathrm{Cl}$ of difference $(-2.8 ;-1.9)$, middle line: $95 \% \mathrm{Cl}(-2.7 ;-1.8)$, bottom line: $95 \% \mathrm{Cl}$ $(-2.4 ;-1.6), * *: 95 \% \mathrm{Cl}(1.1 ; 1.9)$. b AUC showed that difference in response profiles did reach statistical significance when comparing SFC $\times$ MSS area, Kruskal-Wallis (Dunn's) multiple comparisons test, **** indicates $p<0.0001$

report that the amount of cytokine secreted by individual antigen specific $\mathrm{T}$ cells rather than differences in frequencies was the factor responsible for immune deficiencies in patients with HIV infection [27]. No studies have reported correlation between MSS and SFC in HBV infection. Most studies on HBV focus on SFC as the primary response parameter [28-30]. One tuberculosis vaccination study of non-human primates, found that spot size in combination with spot number, was key in determining a protective immune response [31]. We found no correlation between SFC and MSS respectively, but where able to describe similar results regarding SFC combined with MSS.

The three experimentally confirmed (EC) epitopes with highest SI (epitope 11 being HBcAg 18-27 which previously has been described as being highly immunogenic [10, 32, 33]) correlated with observations from previous studies. The three new computer predicted (CP) epitopes HBsCP-7, HBsCP-9 with predicted $K_{\mathrm{D}}<50$ and $\mathrm{HBcCP}-17$ with predicted $K_{\mathrm{D}}>500$, may be worth examining in future studies. Surprisingly we saw a high SI when stimulation with $\mathrm{HBsCP}-17$ despite the high $K_{\mathrm{D}}$ value, and this suggest that the CTL-inducing effect of an antigenic peptide not always correlate with the computer estimated $K_{\mathrm{D}}$ value [8, 9]. However, our results indicate that software both predict new epitopes as well as confirm previously described epitopes.

The liver cellular environment offers opportunities for immune evasion, which may partly explain why the immune response towards HBV frequently fails in the liver. Does this indicate HBV as a well-adapted pathogen - or is it the Th2 biased environment in the liver that permits the path to chronicity? The liver is an important site for $\mathrm{T}$ cell activation, however, the environment is biased towards induction of tolerance. This is partially due to the ongoing synthesis of IL-10 by cells constitutively exposed to traces of endotoxin and other microbial products [34]. In addition, the structure of the liver enables open access of naïve $T$ cells to diverse subsets of antigen presenting cells (APCs). As a result, formation of memory $\mathrm{T}$ cell is lacking in this tissue since $\mathrm{CD}^{+} \mathrm{T}$ cell 

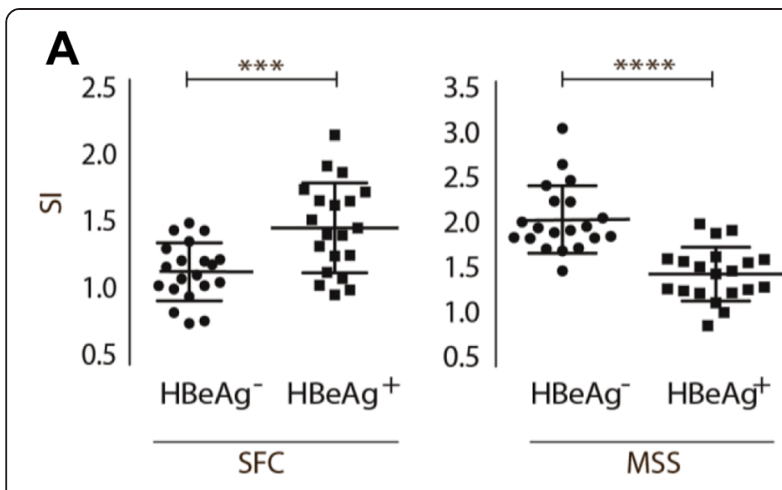

B
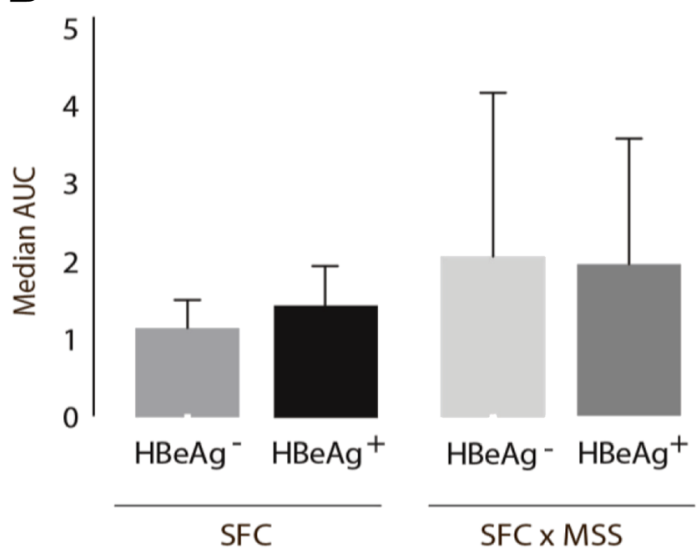

Fig. 4 ELISPOT results of HBeAg positive and negative patients. a Stimulation index (SI) for CHB patients divided in HBeAg positive and $\mathrm{HBeAg}$ negative. Each datapoint represents the mean response to each individual epitope. CHB patients with $\mathrm{HBeAg}$ negative had significantly higher SI of MSS compared to HBeAg positive patients, and the contrary were found in number of spot forming cells, unpaired two-tailed $t$ test with equal SD, HBeAg negative $(N=24)$, HBeAg positive $(N=6),{ }^{* * * *}$ indicates $p<0.0001,{ }^{* * *}$ indicates $p=0.0009$. b AUC did not reach statistical significant difference in Kruskal-Wallis (Dunn's) multiple comparisons test priming occurs without concomitant $\mathrm{CD} 4^{+} \mathrm{T}$ cell activation [35]. Furthermore, in the liver most APCs express PD-L1 providing the capacity to inactivate $\mathrm{T}$ cells. These mechanisms may be a key factor in the immunotolerance in chronic HBV in agreement with ours and the results of the investigations by others, this suggest that IFN- $\gamma$ production is not the single major component in HBV clearance. Previous studies found a long lasting $T$ cell response only after an acute infection [5, 6]. Our findings suggest, however, that these observations should be interpreted with caution. Memory $\mathrm{CD}^{+} \mathrm{T}$ cells can be divided into two subsets, namely central $\left(\mathrm{T}_{\mathrm{CM}}\right)$ and effector $\left(\mathrm{T}_{\mathrm{EM}}\right)$, which predominantly are found in the lymph node and in circulation, respectively. Nevertheless, their individual ability to confer protective immunity is not all clarified. One study found that $\mathrm{T}_{\mathrm{CM}}$ were more efficient in mediating protective immunity resulting in antigen clearance, and that $\mathrm{T}_{\mathrm{EM}}$ converts to $\mathrm{T}_{\mathrm{CM}}$ in a lineage differentiation pathway. Furthermore, these results demonstrate that long-term persistence of memory $\mathrm{T}$ cells is primarily in the form of $\mathrm{T}_{\mathrm{CM}}$ and that 400 days post infection, $95 \%$ of all $\mathrm{T}$ cells were CCR $7^{\text {hi }}$ [36]. This may explain our low response among the resolved HBV patients, since the blood was taken from the periphery, and all donors had been infected more than 2 years ago. Recently, Loggi et al. found the total breadth and magnitude of HBV specific $\mathrm{T}$ cell responses in IFN- $\gamma$ ELISPOT did not differ significantly between groups of CHB and RHB patients [29] in accordance with our results.

We found evidence that HBeAg status and HLA-type affected the amount of IFN- $\gamma$ production. IL-7 signaling is essential to $\mathrm{CD} 8^{+} \mathrm{T}$ cell proliferation and function [37] and persistent viral antigen load suppresses CD127 expression, i.e., the $\alpha$-chain on the IL-7 receptor on primed T cells. Studies have found that CD127 negatively correlates with serum HBV DNA and HBeAg levels in chronic HBV [38]. In addition to the impaired CD127 expression, exhausted HBV-specific T cells in the liver display increased PD-1 expression [39]. In several studies the PD-1/PD-L1 pathway has been shown to contribute

Table 4 Epitope assessment

\begin{tabular}{|c|c|c|c|c|c|c|}
\hline & HBsEC-1 & HBsEC-4 & $\mathrm{HBsCP}-7$ & HBsCP-9 & HBCEC-11 & $\mathrm{HBcCP}-17$ \\
\hline Chronic & 2,2 & 2,4 & 2,2 & 2,2 & 2,8 & 2 \\
\hline Resolved & 1,1 & 1,2 & 1,8 & 1,6 & 1 & 0,9 \\
\hline HLA-A2 & 1,5 & 1,4 & 1,6 & 1,7 & 1,3 & 1,3 \\
\hline Non A2 & 2,9 & 3,1 & 2,6 & 2,7 & 3,1 & 2,6 \\
\hline Chronic HLA-A11 & 4,5 & 5 & 4,3 & 4,4 & 4 & 4 \\
\hline HBeAg positive & 2 & 1,6 & 1,3 & 1,2 & 1,9 & 3 \\
\hline HBeAg negative & 2,2 & 2,6 & 2,4 & 2,5 & 3 & 2,1 \\
\hline
\end{tabular}

The assessment is based on stimulation index of mean spot size. $\mathrm{HBsEC}$ : $\mathrm{HBsAg}$ experimentally confirmed; $\mathrm{HBsCP}: \mathrm{HBsAg}$ computer predicted; $\mathrm{HBcEC}: \mathrm{HBCAg}$ experimentally confirmed; HBcCP: HBcAg computer predicted 
to the suppression of HBV-specific $\mathrm{T}$ cell function and IFN- $\gamma$ secretion is rapidly suppressed despite a continued presence of antigens. This loss of function coincides with the up-regulation of PD-1 [40]. We now report that a higher viral load in HBeAg positive patients influenced the number of HBV-specific T cells. Despite the higher number of SFC, however, the amount of IFN- $\gamma$ produced was impaired compared to patients negative for $\mathrm{HBeAg}$. This suggests that the IFN- $\gamma$ producing subset of T cells may possibly be inactivated or exhausted by PD-1 linkage and CD127 down regulation while $\mathrm{T}$ cell ability to register and bind to the antigen is partly maintained.

To date, no HLA class I allele has been confirmed to be a protective or risk factor of CHB. However, many proposals have been made $[41,42]$ and, indeed, our findings are in support of some of these previous studies. The IFN- $\gamma$ production was significantly higher in $\mathrm{CHB}$ patients with HLA-A11 genotype compared to the other groups, and with the highest SI levels observed among all groups tested (Fig. 3a). It has been reported previously that HLA-A11 may contribute in the development of natural immunity against HBV [43] and HLA-A11 were among the most common genotypes of responders to an HBsAg vaccine [44].

\section{Conclusion}

In conclusion, our study suggests IFN- $\gamma$ mean spot size as an important supplementary marker for $\mathrm{T}$ cell specificity, providing a measurement of the amount of IFN- $\gamma$ when T cells fails to elicit response as calculated from number of specific $\mathrm{T}$ cells. This readout was found to enhance the discriminatory power of the ELISPOT assay and provide more information on the IFN- $\gamma$ response profile of $\mathrm{CHB}$ and RHB patients. Furthermore, we showed that the computer program NetMHC version 3.2 8mer predictions, using Artificial Neural Networks Approximation could be a valuable tool in future studies regarding HLA genotypes and HBV epitopes. Hence, we found 3 immunogenic epitopes not previous described. Finally, our study highlights the role of the HLA-A11 allele in HBV infections with potential implication for both acquiring the disease and as inducing protective immunity by vaccination.

\footnotetext{
Abbreviations

HBV: Hepatitis B Virus infection; IL-10: Interleukin 10; PD-L1: Programmed cell Death Ligand 1; CTL: Cytotoxic T lymphocytes; $K_{D}$ : Dissociation constant: MHC: Major Histocompability Complex; IFN-ү: Interferon gamma; ELISPOT: Enzyme-linked immunosorbent spot; CHB: Chronic Hepatitis B Virus infection; RHB: Resolved Hepatitis B Virus infection; HBsAg: Hepatitis B virus s-antigen; HBCAg: Hepatitis B virus c-antigen; HIV: Human ImmunodeficiencyVirus; HCV: Hepatitis C Virus infection; HBeAg: Hepatitis B virus e-antigen; anti-HBe: Antibodies against HBeAg; anti-HBC: Antibodies against HBCAg; anti-HBs: Antibodies against HBsAg; ELISA: Enzyme-linked immunosorbent assay; HBV DNA: Hepatitis B Virus deoxyribonucleic acid; PBMC: Peripheral Blood Mononuclear Blood Cells; PBS: Phosphate Buffered Saline; FCS: Fetal Calf Serum; DMSO: Dimethyl Sulfoxid; PCR: Polymerase Chain Reaction; AEC: 3-amino-9-ethyl carbazole; SFC: Spot Forming Cell (IFN-y producing cell); MSS: Mean Spot Size; SI: Stimulation Index;
}

ANOVA: Analysis of Variance; EC: Experimentally Confirmed; CP: Computer Predictions; AUC: Area Under the Curve; APC: Antigen Presenting Cells; $T_{C M}$ : Central Memory T cells; $T_{E M}$ : Effector Memory T cells; CCR7 ${ }^{\text {hi: }}$ C-C chemokine Receptor type 7; IL-7: Interleukin 7; CD127: alpha-chain of the IL-7 receptor.

\section{Competing interest}

The authors declare that they have no competing interests.

\section{Authors' contributions}

Nanna-Sophie Brinck-Jensen (NSBJ), Thomas Vorup-Jensen (TVJ), Peter Christian Derek Leutscher (PCDL), Christian Eristrup (CE), Eskild Petersen (EP). NSBJ, TVJ and EP were heads of the study concept and design. NSBJ and PCDL acquired all patient data and blood samples. CE was responsible for the HLA acquisition and interpretation. NSBJ carried out all immunoassays. NSBJ TVJ and CE carried out all analysis and interpretation of data. NSBJ and TVJ drafted the manuscript. TVJ, CE and EP made critical revision of the manuscript for important intellectual content. NSBJ, TVJ and CE carried out statistical analysis. PCDL and CE were in charge of administrative, technical, and material supports. TVJ and EP were the overall study supervisors. All authors read and approved the final manuscript.

\section{Authors' information}

NSBJ is the PhD student enrolled at Aarhus University. She has been part of the Hepatitis $B$ research group for more than 5 years and has been doing HBV related research in Aarhus, Herlev, Beijing and Liverpool, learning different techniques and skills.

TVJ is professor at Department of Biomedicine, Aarhus University, with special responsibilities in biophysical immunology. He is head of the PhD graduate program for biomedicine at Aarhus University.

PCDL is a medical doctor, PhD, at Department of Infectious Diseases, Aarhus University. He is head of the InfCare Hepatitis DK project, a real-time quality database for patients with chronic HBV.

CE is chief physician and associated professor at Department of Clinical Immunology, Aarhus University Hospital. He is head of HIV and hepatitis testing in the Central Denmark Region, Denmark.

EP is professor at Department of Infectious Diseases, Aarhus University, with many years of experience in the field of infectious diseases, tropical diseases and immunological research. He is chief editor of the international peer review journal International Journal of Infectious Diseases.

\section{Acknowledgement}

The authors are grateful to Bettina Winther Grumsen for excellent technical assistance, Carina A. Rosenberg, PhD, for advice, and to the Karen Elise Jensen Foundation, AP Moeller foundation, Else and Mogens WedellWedellsborgs Foundation, Hede Nielsen Foundation and Aase and Ejner Danielsens Foundation for financial support. The funding sources had no involvement in the conduct of the research or article preparation and will not gain neither lose financially from the publication of this manuscript.

\section{Author details}

'Department of Infectious Diseases, Aarhus University Hospital, Palle Juul-Jensens Boulevard 99, 8200 Aarhus N, Skejby, Denmark. ${ }^{2}$ Department of Biomedicine, Aarhus University, Wilhelm Meyers Allé 4, 8000 Aarhus C, Denmark. ${ }^{3}$ Department of Clinical Immunology, Aarhus University Hospital, Palle Juul-Jensens Boulevard 99, 8200 Aarhus N, Skejby, Denmark.

Received: 27 January 2015 Accepted: 15 October 2015

Published online: 02 November 2015

\section{References}

1. Crispe IN. The liver as a lymphoid organ. Annu Rev Immunol. 2009;27:147-63.

2. Bertoletti A, Maini M, Williams R. Role of hepatitis B virus specific cytotoxic T cells in liver damage and viral control. Antiviral Res. 2003;60(2):61-6.

3. Boni C, Fisicaro P, Valdatta C, Amadei B, Di Vincenzo P, Giuberti T, et al. Characterization of hepatitis B virus (HBV)-specific T-cell dysfunction in chronic HBV infection. J Virol. 2007;81(8):4215-25

4. Chisari FV, Isogawa M, Wieland SF. Pathogenesis of hepatitis B virus infection. Pathol Biol (Paris). 2010;58(4):258-66. 
5. Penna A, Artini M, Cavalli A, Levrero M, Bertoletti A, Pilli M, et al. Longlasting memory $T$ cell responses following self-limited acute hepatitis $B$. J Clin Invest. 1996;98(5):1185-94.

6. Rehermann B, Fowler P, Sidney J, Person J, Redeker A, Brown M, et al. The cytotoxic $T$ lymphocyte response to multiple hepatitis $B$ virus polymerase epitopes during and after acute viral hepatitis. J Exp Med. 1995; 181(3):1047-58

7. Sette A, Vitiello A, Reherman B, Fowler P, Nayersina R, Kast WM, et al. The relationship between class I binding affinity and immunogenicity of potential cytotoxic T cell epitopes. J Immunol. 1994;153(12):5586-92.

8. Lee HG, Lim JS, Lee KY, Choi YK, Choe IS, Chung TW, et al. Peptide-specific CTL induction in HBV-seropositive PBMC by stimulation with peptides in vitro: novel epitopes identified from chronic carriers. Virus Res. 1997;50(2):185-94.

9. Nayersina R, Fowler P, Guilhot S, Missale G, Cerny A, Schlicht HJ, et al. HLA $A 2$ restricted cytotoxic $T$ lymphocyte responses to multiple hepatitis $B$ surface antigen epitopes during hepatitis B virus infection. J Immunol. 1993;150(10):4659-71.

10. Yang $X$, Hao $Y$, Liu Z, Chen L, Ding H, Zhao X, et al. Frequencies and characterization of HBV-specific cytotoxic T lymphocytes in self-limited and chronic hepatitis B viral infection in China. J Huazhong Univ Sci Technolog Med Sci. 2009;29(5):567-74

11. Christensen PB, Clausen MR, Krarup H, Laursen AL, Schlichting P, Weis N, et al. Treatment for hepatitis B virus (HBV) and hepatitis C virus (HCV) infection - Danish national guidelines 2011. Dan Med J. 2012;59(6):C4465.

12. Shiffman ML. Management of acute hepatitis B. Clin Liver Dis. 2010;14(1):75-91. viii-ix.

13. Chisari FV, Ferrari C. Hepatitis B virus immunopathogenesis. Annu Rev Immunol. 1995;13:29-60

14. Rehermann B, Pasquinelli C, Mosier SM, Chisari FV. Hepatitis B virus (HBV) sequence variation of cytotoxic T lymphocyte epitopes is not common in patients with chronic HBV infection. J Clin Invest. 1995;96(3):1527-34.

15. Bertoni R, Sidney J, Fowler P, Chesnut RW, Chisari FV, Sette A. Human histocompatibility leukocyte antigen-binding supermotifs predict broadly cross-reactive cytotoxic T lymphocyte responses in patients with acute hepatitis. J Clin Invest. 1997;100(3):503-13.

16. Bertoletti A, Southwood S, Chesnut R, Sette A, Falco M, Ferrara GB, et al. Molecular features of the hepatitis $B$ virus nucleocapsid T-cell epitope 18-27: interaction with HLA and T-cell receptor. Hepatology. 1997;26(4):1027-34.

17. Bertoletti A, Chisari FV, Penna A, Guilhot S, Galati L, Missale G, et al Definition of a minimal optimal cytotoxic T-cell epitope within the hepatitis B virus nucleocapsid protein. J Virol. 1993;67(4):2376-80.

18. Tsai SL, Chen MH, Yeh CT, Chu CM, Lin AN, Chiou FH, et al. Purification and characterization of a naturally processed hepatitis $B$ virus peptide recognized by CD8+ cytotoxic T lymphocytes. J Clin Invest. 1996;97(2):577-84

19. Sobao $Y$, Sugi K, Tomiyama H, Saito S, Fujiyama S, Morimoto M, et al. Identification of hepatitis B virus-specific CTL epitopes presented by HLA-A*2402, the most common HLA class I allele in East Asia. J Hepatol. 2001;34(6):922-9

20. Coleman PF. Detecting hepatitis B surface antigen mutants. Emerg Infect Dis. 2006;12(2):198-203.

21. Lundegaard C, Lund O, Nielsen M. Accurate approximation method fo prediction of class I MHC affinities for peptides of length 8, 10 and 11 using prediction tools trained on 9mers. Bioinformatics. 2008;24(11):1397-8.

22. Bjellqvist B, Basse B, Olsen E, Celis JE. Reference points for comparisons of two-dimensional maps of proteins from different human cell types defined in a $\mathrm{pH}$ scale where isoelectric points correlate with polypeptide compositions. Electrophoresis. 1994;15(3-4):529-39.

23. Guruprasad K, Reddy BV, Pandit MW. Correlation between stability of a protein and its dipeptide composition: a novel approach for predicting in vivo stability of a protein from its primary sequence. Protein Eng. 1990;4(2):155-61.

24. Ikai A. Thermostability and aliphatic index of globular proteins. J Biochem. 1980;88(6):1895-8

25. Rosenberg C, Bovin NV, Bram LV, Flyvbjerg E, Erlandsen M, Vorup-Jensen T, et al. Age is an important determinant in humoral and $T$ cell responses to immunization with hepatitis B surface antigen. Hum Vaccin Immunother. 2013;9(7):1466-76.

26. Krarup $\mathrm{H}$, Andersen $\mathrm{S}$, Madsen PH, Christensen PB, Laursen AL, BentzenPetersen A, et al. HBeAg and not genotypes predicts viral load in patients with hepatitis B in Denmark: a nationwide cohort study. Scand J Gastroenterol. 2011;46(12):1484-91.
27. Helms T, Boehm BO, Asaad RJ, Trezza RP, Lehmann PV, Tary-Lehmann M. Direct visualization of cytokine-producing recall antigen-specific CD4 memory T cells in healthy individuals and HIV patients. J Immunol. 2000;164(7):3723-32

28. Ouyang L, Li X, Liang Z, Yang D, Gong F, Shen G, et al. CD8low T-cell subpopulation is increased in patients with chronic hepatitis $B$ virus infection. Mol Immunol. 2013;56(4):698-704.

29. Loggi E, Bihl FK, Cursaro C, Granieri C, Galli S, Brodosi L, et al. Virus-specific immune response in $\mathrm{HBeAg-negative} \mathrm{chronic} \mathrm{hepatitis} \mathrm{B:} \mathrm{relationship} \mathrm{with}$ clinical profile and HBsAg serum levels. PLoS One. 2013;8(6):e65327.

30. Gehring AJ, Ho ZZ, Tan AT, Aung MO, Lee KH, Tan KC, et al. Profile of tumor antigen-specific CD8 T cells in patients with hepatitis B virus-related hepatocellular carcinoma. Gastroenterology. 2009;137(2):682-90.

31. Sibley LS, White AD, Marriott A, Dennis MJ, Williams A, Marsh PD, et al. ELISPOT refinement using spot morphology for assessing host responses to tuberculosis. Cells. 2012;1(1):5-14.

32. Shi TD, Wu YZ, Jia ZC, Zou LY, Zhou W. Therapeutic polypeptides based on HBV core 18-27 epitope can induce CD8+ CTL-mediated cytotoxicity in HLA-A2+ human PBMCs. World J Gastroenterol. 2004;10(13):1902-6.

33. Liu J, Chen KY, Ren EC. Structural insights into the binding of hepatitis $B$ virus core peptide to HLA-A2 alleles: towards designing better vaccines. Eur J Immunol. 2011;41(7):2097-106.

34. Knolle PA, Uhrig A, Hegenbarth S, Loser E, Schmitt E, Gerken G, et al. IL-10 down-regulates $T$ cell activation by antigen-presenting liver sinusoidal endothelial cells through decreased antigen uptake via the mannose receptor and lowered surface expression of accessory molecules. Clin Exp Immunol. 1998;114(3):427-33.

35. Warren A, Le Couteur DG, Fraser R, Bowen DG, McCaughan GW, Bertolino P. $T$ lymphocytes interact with hepatocytes through fenestrations in murine liver sinusoidal endothelial cells. Hepatology. 2006;44(5):1182-90.

36. Wherry EJ, Teichgraber V, Becker TC, Masopust D, Kaech SM, Antia R, et al. Lineage relationship and protective immunity of memory CD8 T cell subsets. Nat Immunol. 2003:4(3):225-34.

37. MacPherson PA, Fex C, Sanchez-Dardon J, Hawley-Foss N, Angel JB. Interleukin-7 receptor expression on CD8(+) T cells is reduced in HIV infection and partially restored with effective antiretroviral therapy. J Acquir Immune Defic Syndr. 2001;28(5):454-7.

38. LV G, Ying L, Ma WJ, Jin X, Zheng L, Li L, et al. Dynamic analysis of CD127 expression on memory CD8 T cells from patients with chronic hepatitis $B$ during telbivudine treatment. Virol J. 2010;7:207-422X-7-207.

39. Fisicaro $P$, Valdatta C, Massari M, Loggi E, Biasini E, Sacchelli L, et al. Antiviral intrahepatic T-cell responses can be restored by blocking programmed death-1 pathway in chronic hepatitis B. Gastroenterology. 2010;138(2):682-93. 693.e1-4

40. Maier H, Isogawa M, Freeman GJ, Chisari FV. PD-1:PD-L1 interactions contribute to the functional suppression of virus-specific CD8+ T lymphocytes in the liver. J Immunol. 2007;178(5):2714-20.

41. Thio CL, Thomas DL, Karacki P, Gao X, Marti D, Kaslow RA, et al. Comprehensive analysis of class I and class II HLA antigens and chronic hepatitis B virus infection. J Virol. 2003;77(22):12083-7.

42. Wu YF, Wang LY, Lee TD, Lin HH, Hu CT, Cheng ML, et al. HLA phenotypes and outcomes of hepatitis B virus infection in Taiwan. J Med Virol. 2004:72(1):17-25.

43. Akcam Z, Sunbul M, Durupinar B, Eroglu C, Esen S, Leblebicioglu $H$. Tissue types as prognostic risk factor in hepatitis B virus infection. Indian J Gastroenterol. 2002;21(4):139-41.

44. Das K, Gupta RK, Kumar V, Singh S, Kar P. Association of HLA phenotype with primary non-response to recombinant hepatitis $B$ vaccine: a study from north India. Trop Gastroenterol. 2004;25(3):113-5. 